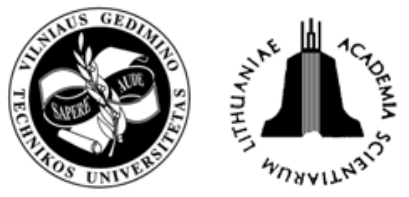

ISSN 1648-4142 print / ISSN 1648-3480 online TRANSPORT

www.transport.vgtu.lt

\title{
IMPROVEMENT OF ROAD SAFETY USING PASSIVE AND ACTIVE INTELLIGENT VEHICLE SAFETY SYSTEMS
}

\author{
Aldona Jarašūnienè $\dot{1}^{1}$, Gražvydas Jakubauskas² \\ Transport Research Institute, Vilnius Gediminas Technical University, \\ Plytines g. 27, LT-10105 Vilnius, Lithuania \\ E-mails: ${ }^{1}$ aldonaj@ti.vgtu.lt, ${ }^{2}$ Grazvydas.Jakubauskas@ti.vgtu.lt
}

Received 2 January 2007; accepted 10 September 2007

\begin{abstract}
Following the measures foreseen in the Transport White Paper 2001, situation of road safety has improved. Road fatalities have declined by more than $17 \%$ since 2001 in the EU. However, with around 41600 deaths and more than 1.7 million injured in 2005, road remains the least safe mode of transport and objectives to halve the number of fatalities on road by 2010 is most likely not feasible to achieve. Therefore a need for the intelligent vehicle safety systems, that enable to raise the level of road safety, is much higher than ever before.

The Intelligent Vehicle Safety Systems ensure a superior safety on road would it be vehicle-based or infrastructure-related systems. These can be divided into passive and active safety applications where the former help people stay alive and uninjured in a crash, while the latter help drivers to avoid accidents. Some of the most promising (e-call) and the most used (ABS, ESP) systems are analised more specifically in the paper. Possible solutions to deploying intelligent transport systems in Lithuania are also introduced.
\end{abstract}

Keywords: IVSS, eSafety, intelligent car, eCall, active safety, passive safety.

\section{Introduction}

Problems such as traffic congestion, global warming and environmental sustainability are forcing us to review our long-term plans for transport [1-7]. Our aim must be to develop and improve the safety, security and effectiveness of the transportation systems where we can, building on the investments made in past decades. At the same time we must anticipate and be ready for the problems and challenges that are ahead. This is where ITS can play a vital part [8-13].

Road vehicles provide much better protection for their drivers and passengers than was the case a decade or even several years ago. Nevertheless there is still much to do in order to improve protection of vulnerable users in the event of accidents. Intelligent Vehicle Safety Systems (IVSS) - or so called eSafety systems, are new automotive systems combining mechanical, micro-electric, communication and information technology and are aimed at significantly reducing the road accidents rate and their consequences. These systems create superior safety through active technology and contribute to safety on roads by preventing vehicle collisions and consequently helping to reduce injuries and deaths on the roads [2].

The eSafety initiative was established in April 2002 as a public-private partnership of the European Commission and industries having an interest in informa- tion-based road safety systems, e.g. car manufacturers, road operators, telecom companies and transport service providers.

The eSafety aims at increasing road safety and road transport efficiency through the use of Intelligent integrated safety systems. These systems use information and communication technologies for vehicle safety [3].

\section{Analysis of situation of safety on roads: a need for IVSS}

Over 42000 road users are killed in European Union (EU) countries annually and around 3.5 million are injured. This accounts for an annual cost of over 160 billion Euros and untold pain and suffering of the victims and their relatives. Looking at fatality numbers, car occupants are the largest single casualty group. They comprise $57 \%$ of total EU road deaths, with the majority of car occupant casualties sustained in side and frontal impacts. Looking at fatality risk however, the traffic system is less safe for the more vulnerable road users, where the risk of death on EU roads is substantially higher than for car occupants. Indeed, for pedestrians and cyclists the risk is $8-9$ times higher and for motorcyclists it is 20 times higher [4].

In the year 2001, a joint target on improving safety on roads was proposed: to halve the number of people killed on the roads from 50000 in 2001 to no more than 
25000 by the year 2010. Fig. 1 indicates a comparison of the trends with the real situation on this objective.

According to the forecasts, a fall reached to date is far to small to reach the target by 2010: at this rate (a fall of $17.5 \%$ over four years), number of people killed in the road accidents are likely to stand at 35500 [5], what is a surplus of more than 10000 , i.e. above the target of 25000.

This shows a strong need for the deployment of intelligent transport systems (ITS) and a fruitful co-operation amongst all stakeholders.
Timely and effective deployment of IVSS will undoubtedly make the 2010's target more feasible.

\section{Analysis of IVSS systems}

When considering the factors that are most important before buying a car, the most important one, apart from the price, is safety. According to Eurobarometer's survey initiated by the European Commission, the drivers find this factor the same important as fuel consumption when choosing amongst different brands or models. In Fig. 2. the results of the questionnaire are provided,

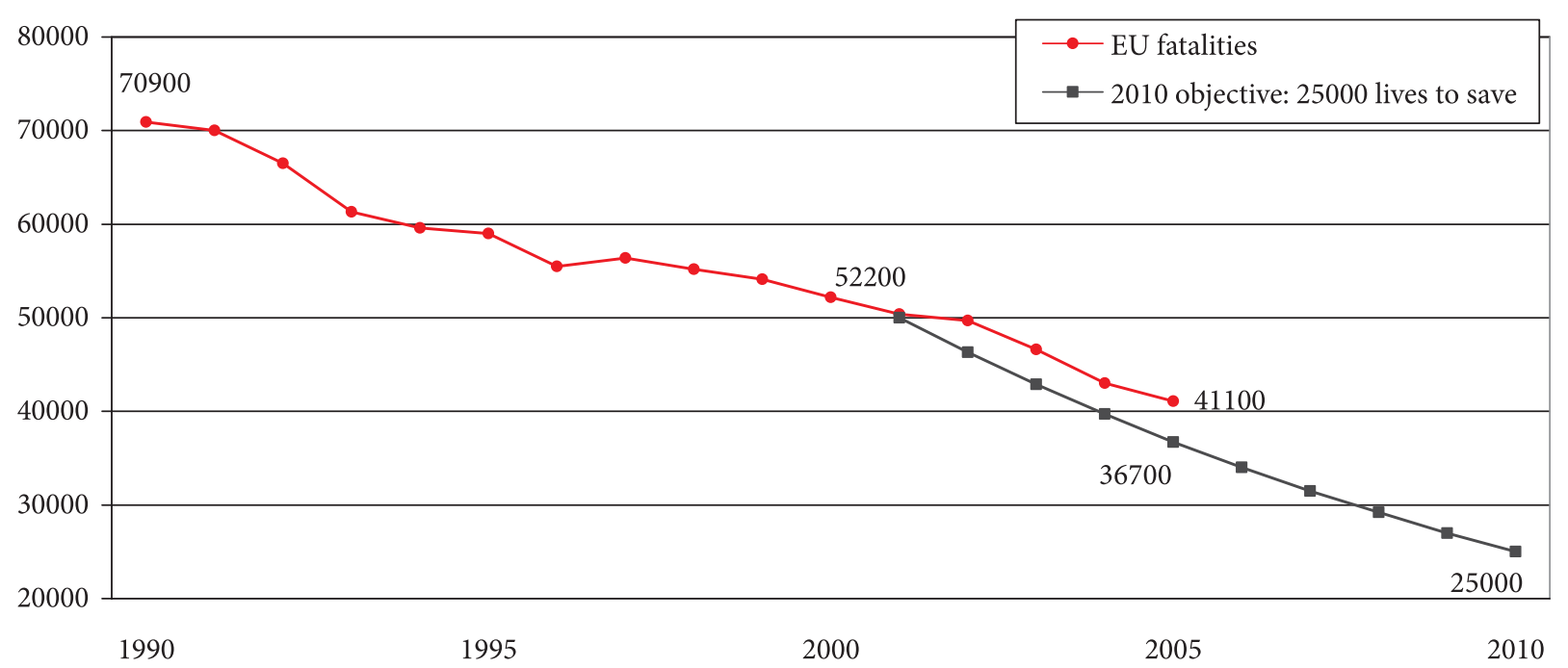

Fig. 1. Situation on reaching the objectives of the White Paper 2001

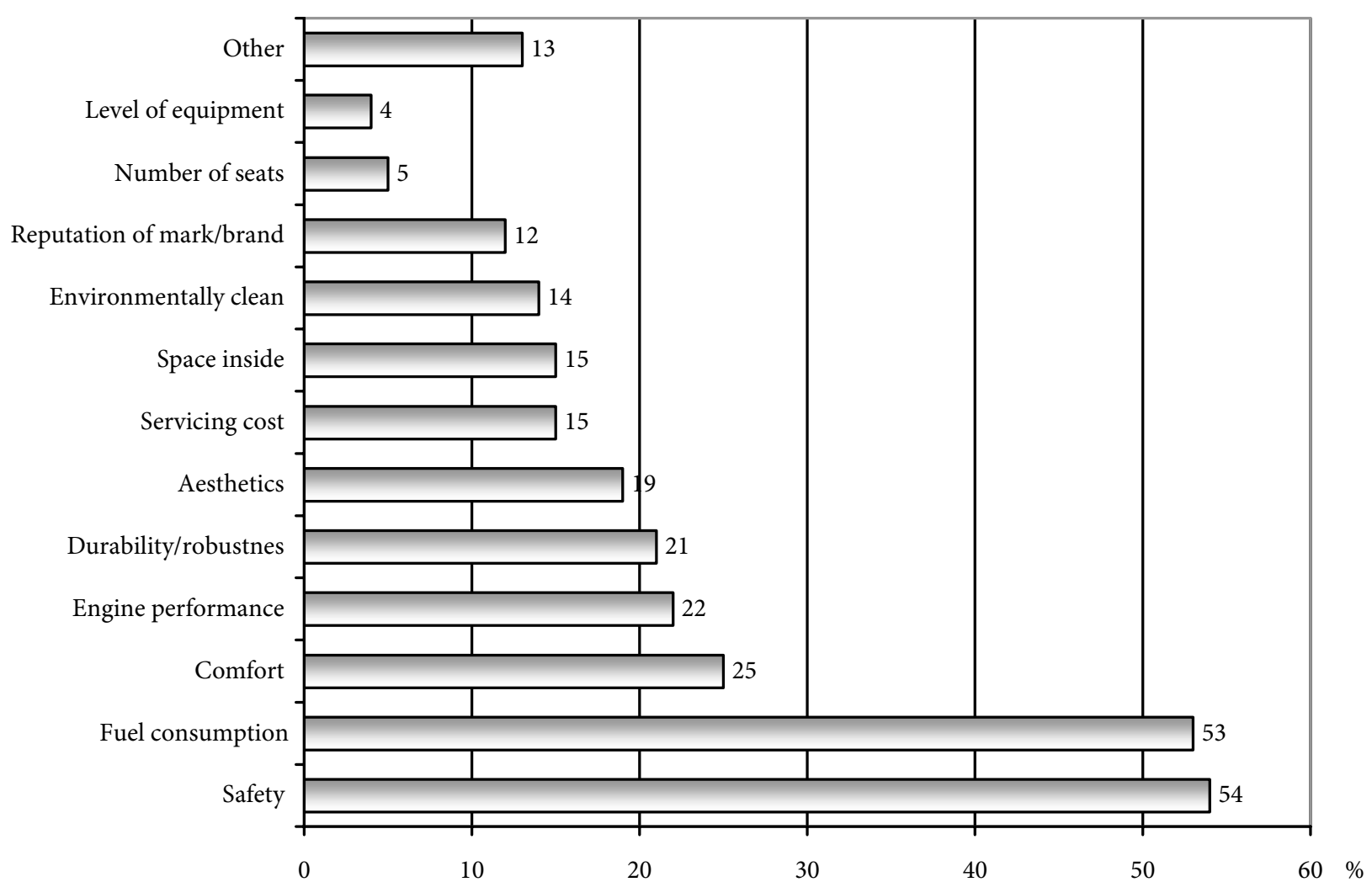

Fig. 2. Factors having effect when choosing a car 


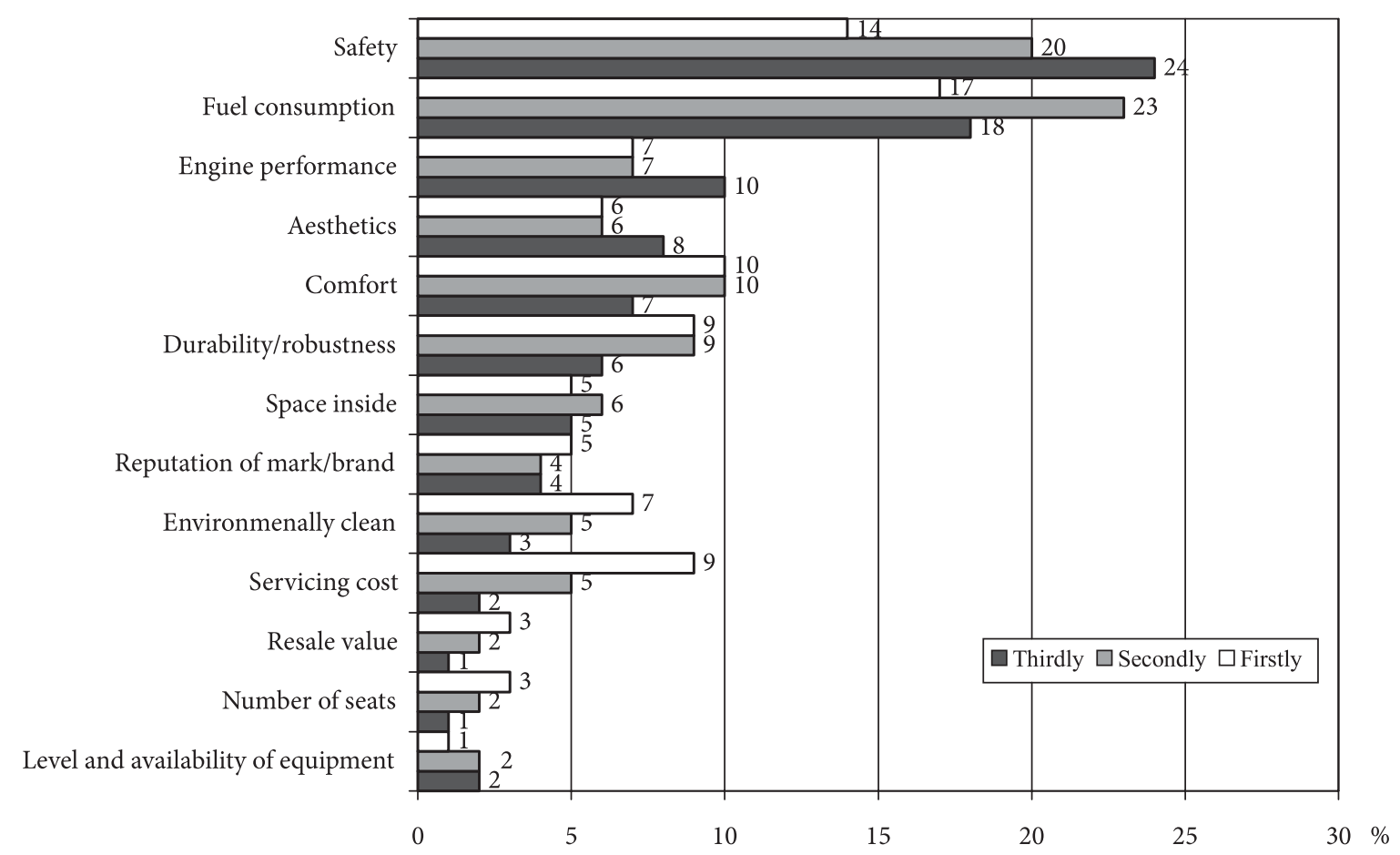

Fig. 3. Prioritisation of the factors having effect when choosing a car

answering the question: "Suppose you were to buy a car today, be it new or second - hand, which factors, apart from the price, would make you lean towards one model over another?"[6].

Given the same question, the respondents were asked to prioritise the factors that determine willingness to buy one or another model. The safety factor seems to be always one of the most important ones as well (see Fig. 3).

IVSS are divided into two groups - vehicle-based and infrastructure-related systems. These can be divided into active and passive safety applications. Passive safety features help people stay alive and uninjured in a crash, while active safety features help drivers avoid accidents [2].

The Table below indicates a possible use of IVSS during pre-crash, accident-time, and post-crash periods downstream from the lowest crash probability to postcrash moment. The examples given are divided by their direct functions or aims, nature and type (Table 1).

The previously mentioned $e$ Safety initiative has defined a list of the most effective IVSS systems (eSafety systems). The chart below indicates the grouping of these systems by vehicle-based and infrastructure-related systems (Fig. 4).

Majority of the systems are to be implemented or to be more actively used as standard equipment in the nearest future. In-vehicle emergency call or (eCall) is seen as a priority action: The European Commission has proposed an urgent set of actions to restart moves to roll out eCall in Europe. The Commission-industry action plan agreed in 2005 set out eCall systems to be implemented as a standard option in all new-type cars in Europe by 2010 [7]. Nevertheless, while there has been significant progress at European level, some Member States have
Table 1. Active and passive safety systems

\begin{tabular}{|c|c|c|c|}
\hline & $\begin{array}{l}\text { Aims of } \\
\text { IVSS }\end{array}$ & Nature of IVSS & Examples of IVSS \\
\hline \multirow{3}{*}{ 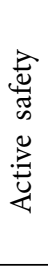 } & To inform & $\begin{array}{c}\text { Foresighted driving } \\
\text { systems }\end{array}$ & $\begin{array}{c}\text { Digital map-based } \\
\text { systems }\end{array}$ \\
\hline & To support & $\begin{array}{c}\text { Warning and } \\
\text { assistance systems }\end{array}$ & $\begin{array}{l}\text { Lane, distance, and } \\
\text { speed warning }\end{array}$ \\
\hline & To intervene & $\begin{array}{l}\text { Pre-crash systems } \\
\text { and reversible } \\
\text { protection systems }\end{array}$ & $\begin{array}{c}\text { Brake assistance, } \\
\text { active control of a } \\
\text { vehicle }\end{array}$ \\
\hline \multicolumn{4}{|c|}{ Accident } \\
\hline \multirow{3}{*}{ 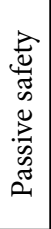 } & $\begin{array}{l}\text { Aid in minor } \\
\text { accidents }\end{array}$ & Soft-level systems & $\begin{array}{l}\text { Airbags, crash- } \\
\text { worthiness, }\end{array}$ \\
\hline & $\begin{array}{l}\text { Aid in severe } \\
\text { accidents }\end{array}$ & Hard-level systems & $\begin{array}{c}\text { Intelligent restraint } \\
\text { systems }\end{array}$ \\
\hline & $\begin{array}{l}\text { Post-crash } \\
\text { aid }\end{array}$ & Rescue systems & eCall. \\
\hline
\end{tabular}

been slow to invest in infrastructure, and industry now refuses further action.

The principle of e-call is based on giving precise coordinates of the location of an accident to the emergency services, which are responsible for the help [8]. It is foreseen to include in the e-call systems stakeholders from public organisations as well as from telecom companies, service providers and car manufacturers.

The in-vehicle eCall is an emergency call generated either manually by the vehicle occupants or automatically via activation of in-vehicle sensors after an accident. When activated, the in-vehicle eCall device will establish an emergency call carrying both voice and data directly to the nearest emergency services (normally to the nearest 112 Public Safety Answering Point (PSAP) [2]. 


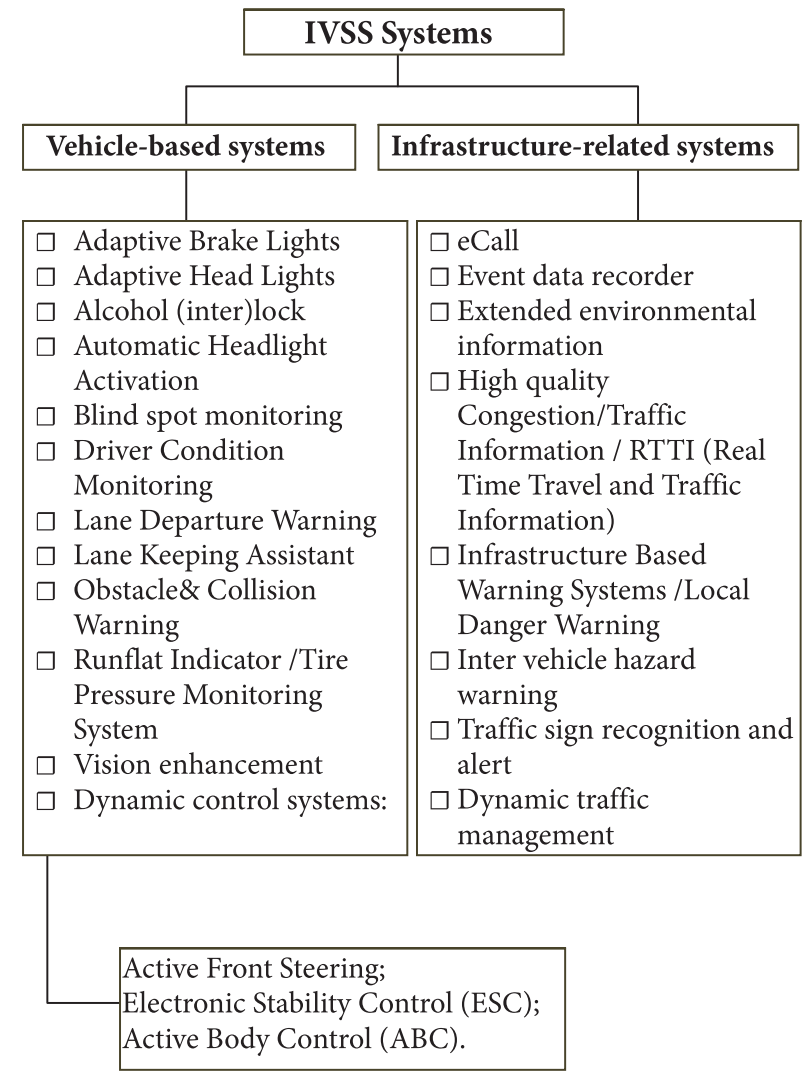

Fig. 4. IVSS systems

The voice call enables the vehicle occupants to communicate with the trained eCall operator. At the same time, a minimum set of data will be sent to the eCall operator receiving the voice call. The minimum set of data contains information about the incident, including time, precise location, the direction the vehicle was travelling and vehicle identification.
E-call is perceived as an useful option amongst the drivers - the before-mentioned survey proved that drivers see it as one of the most important intelligent safety systems ranking it third.

Overall drivers well perceive the usefulness of IVSS. Given the question as to which IVSS they would like to have in their car, the majority would like have each of the 10 provided in the questionnaire. The share of drivers that would like to have IVSS in their car, even if they think it is not a useful system, ranges from $75 \%$ concerning ABS to $52 \%$ concerning lane departure warning system [6]. The diagram below indicates how European drivers perceive the usefulness of 10 given systems (Fig. 5).

Blue line represents the percentage of drivers that think of these systems as useful and want to have them in their new car. The red one represents the share of the drivers that think of the system as not useful and do not want to have them in their new car.

Not surprisingly the respondents accentuated ABS and ESP systems: the best-known and the most widely used systems and their features are well known and perceived amongst the drivers. Although ABS (Anti-Lock Braking System) originally was developed for aircraft braking systems and first put to use in cars in the late 1970s, it is now equipped in $91 \%$ of new vehicles. Penetration rate is $66 \%$ in the whole vehicle park in Europe [6].

ABS uses computer-controlled valves to limit the pressure delivered to each slave cylinder. If a wheel locks up, steering input cannot affect the car's direction. With ABS, no matter how hard the pedal is pressed, each wheel is prevented from locking up and skidding is pre-vented. Since ABS pumps the brakes, a driver can apply constant pressure on the brake pedal and concentrate on steering the car. This allows the driver to regain control during inclement weather or quickly avoid a collision.

ESP (Electronic Stability Program) is newer and now so widely used - first used in 1995 , it reached the

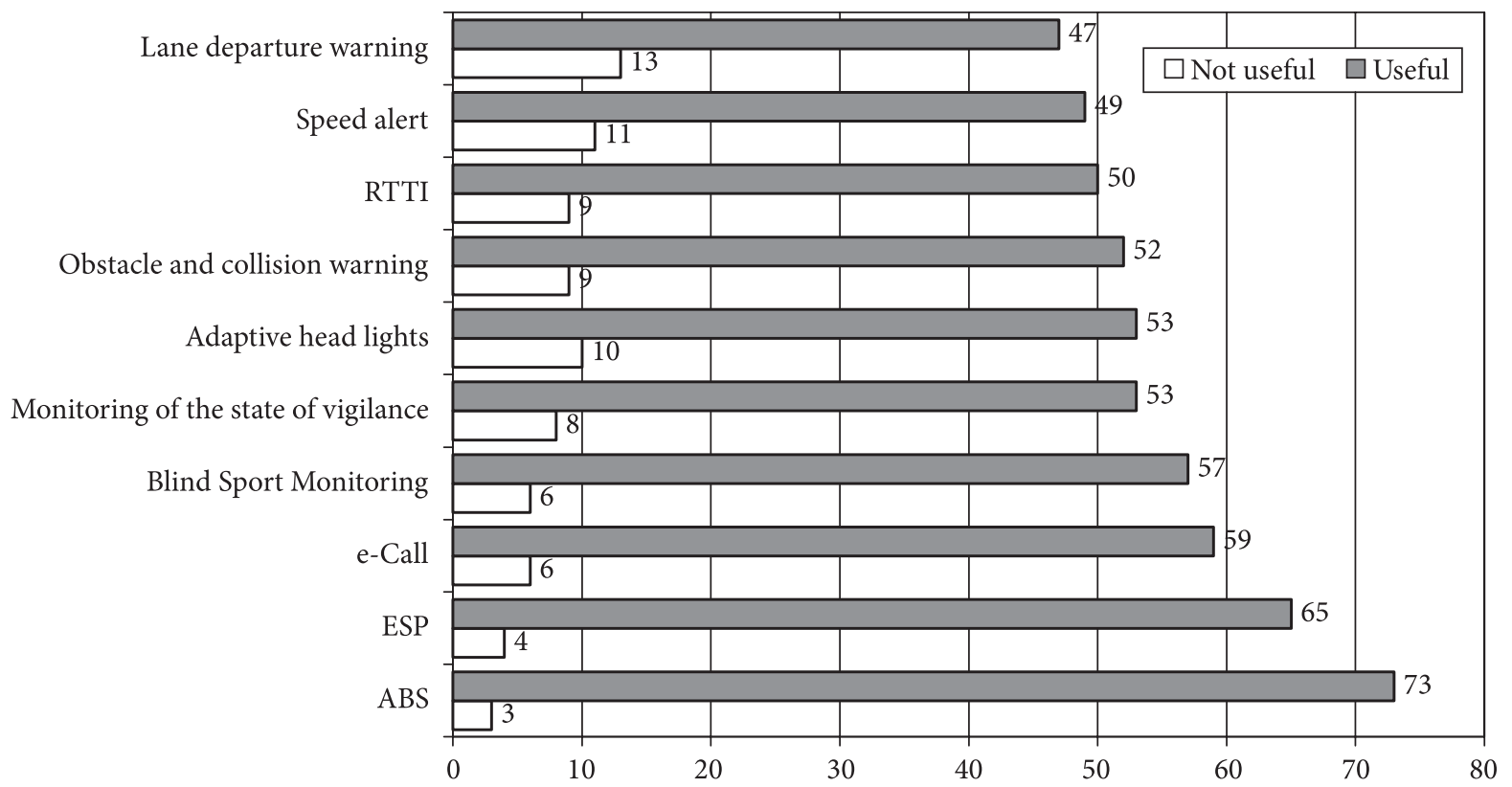

Fig. 5. How drivers perceive IVSS systems 


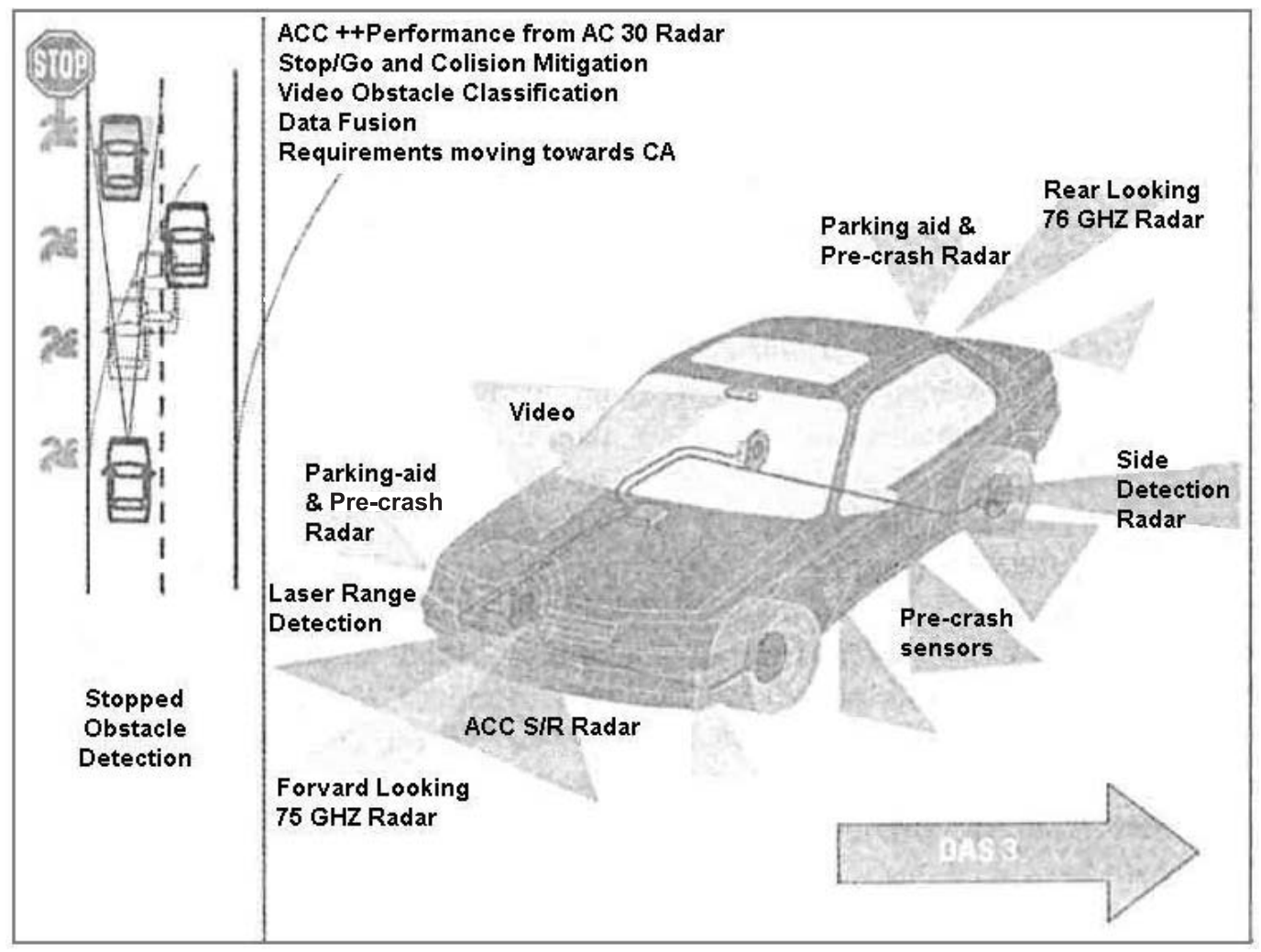

Fig. 6. Driver assistance system

penetration rate of $40 \%$ in new cars in 2005 [6]. ESP is a system stabilising the vehicle and preventing skidding in critical situations. Based on ABS, ESP detects the onset of a slide and automatically applies the brakes to individual wheels to correct the slide and prevent spinning.

It is needless to say how useful might be the Blind Spot Monitoring System. This system warns the driver about nearby obstacles in the blind spot. Since 2004 it is available in some new vehicles but still it is in its early stage of deployment (Fig. 6).

Other systems are not so well perceived because of the limited knowledge of the drivers about them. Nevertheless they all are thought to be useful and effective amongst the drivers. The use of all these systems in the nearest future is foreseen as unavoidable necessity striving to achieve significant progress towards the reduction of fatalities on roads.

\section{Estimation of possible technical solutions to ITS deployment in Lithuania}

Firstly, with the aim of integration of Lithuanian ITS into the EU system of ITS it is necessary to orient to the KAREN project, which is a project on elaboration of ITS architecture guidelines for deployment of active and operating ITS in the EU by 2010 and later [14].

In the process of creating the ITS architecture for public organisations and business stakeholders it is necessary to decide upon the form of the architecture which should be created. Such form may be one of the following three types:
- Structure architecture, i.e. the architecture consisting of consumer demands and functional aspect. It may be used in the process of creating the architectures of the following two types and it is the only type of architecture really applicable to national level architectures.

- Legacy architecture, having physical, communication and other aspects plus capacities. It may be used on the national, regional and local levels with concretisation of ITS deployment needs. The content of physical aspect can be fixed or limited.

- Service architecture, which is like the legacy architecture, however it only supports/maintains the exclusive service, as for example management of road accidents, travel information, public transport management, etc.

ITS architecture has to be developed with the aim of coordination of all ITS components into one framework structure, so that their interoperability could be reached in the delivery of necessary services to customers.

Specific architecture can be expressed by multiple forms. It is necessary that stakeholders should understand and approve the concepts and functions that inform about the development of ITS operations and institutional architectures. On their part, ITS designers have to work with logical, physical and telecommunication architecture that will present operational and functional requirements.

Lithuanian ITS architecture should be sufficiently enough adjusted to defined local requirements. This will 
be expressed with the view to the functional requirements, logistical architecture and organisational architecture $[7,12,13]$.

Each aspect of architecture is related to ITS implementation plans and can precisely indicate where it will be important to ensure interinstitutional agreements of common operation, or to define the value of common regional standards used. Properly carried out and well explained to society the ITS architecture analysis will demonstrate the whole range of interrelations necessary for operators in different institutions with the aim of efficient delivery of ITS services. Examples:

- Interoperability of intended new or of modernised existing ITS traffic regulation systems and travel information services;

- Stock of available and necessary for the region data transmission and telecommunication systems;

- Opportunities rendered by new and modernised data accumulation and traffic management methods with the aim of delivering real time information.

ITS architecture can not be created in the abstract. It is necessary to regard national peculiarities and especially local situations, for instance, when certain stakeholders may have already had significant investments in legacy systems. It may become that the main ITS architecture analysis factor is influencing the regional architecture in two ways - both as an opportunity and as a restriction. Experts should pay their particular attention to the necessity of seeking the operation of certain systems coordinated on the national level $[7,11-12]$.

\section{Conclusions}

1. Further deployment of IVSS ensures the necessary preconditions for reductions of road accidents and fatalities.

2. Existing situation: real time travel information is not delivered.

3. Transport flows on main roads and urban streets are constantly growing, congestion becoming a threat of traffic safety.

4. Traffic management and travel safety do not meet the growing demands of traffic actors, ITS services are not delivered to travellers.

5. ITS initiatives are faint; also there is insufficient support on the governmental scale.

6. Due to the lack of good quality road transport information infrastructure, and as a maritime country through which two main international transport corridors of European importance are going, Lithuania does not exploit all available transit and tourism potentials.

7. Measures of road information infrastructure improvement in Lithuania are insufficiently applied, and their efficiency in road safety is poor. Objectives: creating of modern road transport information infrastructure by technical parameters and by service quality corresponding to the standards of EU
Member States, and accordingly integrated into the EU transport information infrastructure enabling good road safety on Lithuanian roads. Tasks:

- Improvement of road information infrastructure.

- Improvement of traffic conditions on roads and streets.

- Enhancement of traffic safety.

\section{References}

1. Intelligent transportation system in work zones. A case study. USA. $2005.50 \mathrm{p}$.

2. eSafety - Making Europe's roads safer for everyone, eSafety support. Brussels, 2001, p. 2-10.

3. eSafety - Improving road safety using information \& communication technologies. eSafety Factsheet 48, December 2006.

4. European road safety action programme mid-term review. Communication form the Commission. Brussels, 22/02/2006 COM(2006) 74 final.

5. Mid-term review of the European Commission's 2001 Transport White Paper "Keep Europe moving: a transport policy for sustainable mobility". 2006.

6. European Commission, Special EUROBAROMETER 267 Use of Intelligent systems in vehicles, November 2006, p. 17-43.

7. Communication from the Commission to European Parliament, the European Economic and Social Committee and the Committee of the Regions On the Intelligent Car Initiative Raising Awareness of ICT for Smarter, Safer and Cleaner Vehicles. Brussels, 15.2.2006, COM(2006) 59 final.

8. Intelligent Transport Systems and Services. ITS - Part of Everyone's Daily Life. ERTICO - ITS Europe Navigation Technologies. Brussels, 2002, p. 10-41.

9. Definition and scope of ECTRI's long-term strategy. Report ECTRI's 2004. Budapest, 2004. 23 p.

10. GRAFU, F. D. Intelligent transportation system - networking architecture. In TST-05. International conference in Poland. Katowici, 2005, p. 56-63.

11. BAUBLYS, A. Introduction to the theory of transport system (Transporto sistemos teorijos ivvadas). Vilnius: Technika, 1997. 298 p. (in Lithuanian).

12. JARAŠŪNIENĖ, A. Analysis of possibilities and proposals of Intelligent transport systems (ITS) implementation in Lithuania. Transport, 2006, Vol. XXI, No. 4, p. 239-245.

13. JARAŠŪNIENE, A. Intelligent transport systems (ITS) in the long-term period. In The 6th International Conference "Relstat-2006". Latvia, 2006, p. 54-60.

14. PIARC ITS Handbook- $2^{\text {nd }}$ edition. The Intelligent transport systems handbook. 2004. $351 \mathrm{p}$. 